\title{
Nutrient Cycling Study
}

Peter A. Pryfogle

September 2005

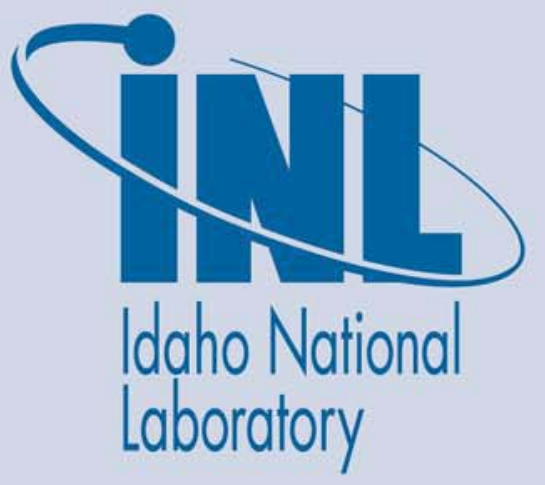

The INL is a U.S. Department of Energy National Laboratory operated by Battelle Energy Alliance 
INL/EXT-09-16474

\title{
Nutrient Cycling Study
}

\author{
Peter A. Pryfogle
}

September 2005

\section{Idaho National Laboratory \\ Idaho Falls, Idaho 83415}

http://www.inl.gov

Prepared for the

U.S. Department of Energy

Assistant Secretary for Energy Efficiency and Renewable Energy

Under DOE Idaho Operations Office

Contract DE-AC07-05ID14517 


\begin{abstract}
Microorganisms obtain nutrients and energy for cellular processes and growth through oxidation/reduction reactions, which are catalyzed by specific enzymes. Microbially-mediated oxidation/reduction reactions are of considerable interest since they form the basis for a wide range of industrial mineral leaching, wastewater treatment, and environmental remediation applications. When sulfide is produced by bacteria, it is considered to be a key factor in the corrosion of steel and concrete infra-structure. The microbial cycling of sulfur is of interest for geothermal facilities in that sulflur is present in most geothermal fluids, and steel and concrete are common materials of construction. The study conducted developed measurement techniques for understanding how consortia of organisms from the geothermal facilities utilize sulfur and iron for metabolic activity; and in turn, what role that activity plays in initiating or promoting the development of a biofilm on plant substrates. This report describes the set-up and operation of bioreactor for evaluating the response of colonies of geothermal organisms to changes in nutrient and environmental conditions.
\end{abstract}




\section{ACKNOWLEDGMENTS}

This document is an interim report that was prepared to prior to the Department of Energy's termination of research activities. This work was supported by the U. S. Department of Energy, Assistant Secretary for Energy Efficiency and Renewable Energy, under DOE Idaho Operations Contract DEAC07-05ID14517. 


\section{Table of Contents}

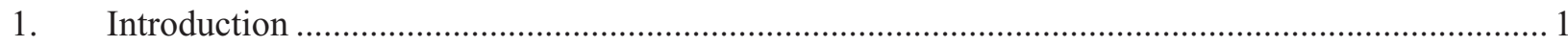

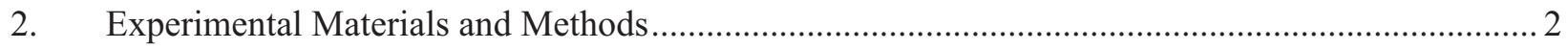

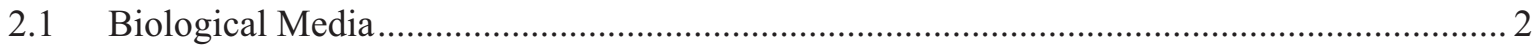

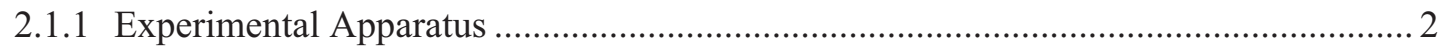

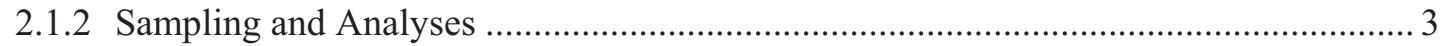

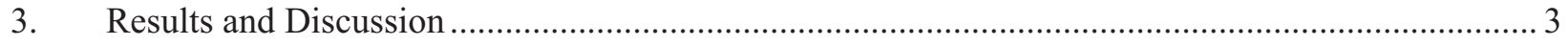

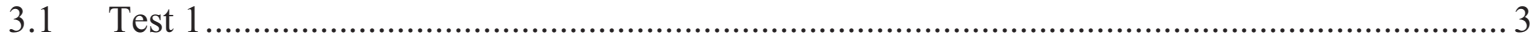

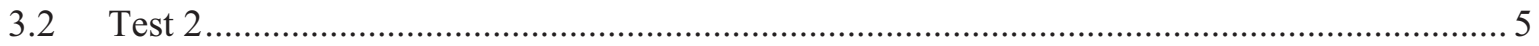

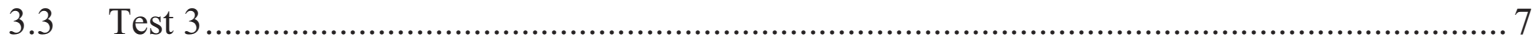

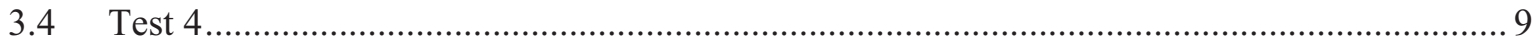

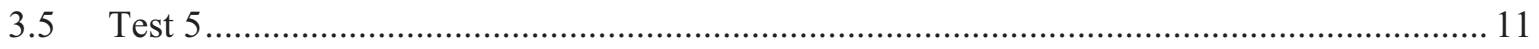

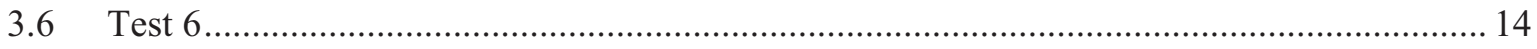

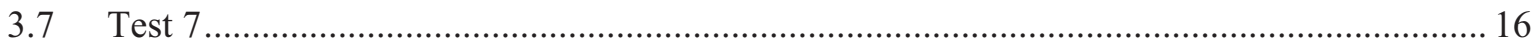

4. Conclusions and Recommendations for Future Work …............................................................ 19 


\section{Nutrient Cycling Study}

\section{INTRODUCTION}

Microorganisms obtain nutrients and energy for cellular processes and growth through oxidation/reduction reactions, which are catalyzed by specific enzymes. Oxidation reduction, or redox, reactions involve the transfer of electrons from one reactant to another. This transfer occurs through the donation of one or more electrons from a material substrate, called the electron donor, and accepted by the electron acceptor, leading to changes in the chemical state of both the donor and acceptor. In a redox reaction, the electron donor is oxidized and the electron acceptor is reduced. And, because electrons cannot exist independently, an oxidation cannot occur without a subsequent reduction. In biochemical reactions, redox reactions may also involve the transfer of hydrogen atoms, i.e. when the electron is removed the hydrogen atom becomes a proton.

The tendency for a material to donate or accept electrons is expressed by its reduction potential. Substances with large positive reduction potentials readily accept electrons. Substances with lower or negative reduction potentials readily give up electrons. In systems with abundant carbon and nutrients for supporting microbial growth, there is a well-defined sequence of redox reactions that occur. Initially, nearly all the $\mathrm{O}_{2}$ is consumed. When the $\mathrm{O}_{2}$ is nearly depleted, nitrate $\left(\mathrm{NO}_{3}\right)$ is reduced to $\mathrm{NO}_{2}{ }^{-}, \mathrm{NH}_{4}$, $\mathrm{N}_{2} \mathrm{O}$, or $\mathrm{N}_{2}$ through various reactions. After the nitrate is used, the dissolution of $\mathrm{Fe}^{3+}$ to $\mathrm{Fe}^{2+}$ occurs. Finally, when the potential drops even lower, sulfate reduction becomes the dominant redox reaction leading to the formation of $\mathrm{HS}^{-}, \mathrm{H}_{2} \mathrm{~S}$, and $\mathrm{S}_{2} \mathrm{O}_{3}$.

A number of studies have been published on various aspects of microbially-mediated oxidation/reduction. These reactions are of considerable interest since they form the basis for a wide range of industrial mineral leaching, wastewater treatment, and environmental remediation applications. In addition, sulfide production by bacteria is considered to be a key factor in the corrosion of steel and concrete infra-structure, including petroleum and water transporting pipelines and canals. Many of these studies are directed at identifying and measuring the impact of specific organisms known to participate in a particular redox pathway. In actual field environments these interactions are far more complex. For example, in the case of steel corrosion, sulfate-reducing organisms may indirectly influence corrosion through the production of aggressive species, such as bisulfides or hydrogen sulfide. Intermediate metabolic products, such as thiosulfate, may also be produced that are equally corrosive. The interaction with iron may produce an iron sulfide coating, enhancing corrosion through changes in cathodic depolarization. In addition, the physiochemical characteristics of the liquid environment, including $\mathrm{pH}$, ionic composition, and/or oxygen levels can modify reaction pathways, eventually changing them from passivating to corrosive or vice versa.

The particular goal of this study is to develop measurement techniques for understanding how consortia of organisms from the geothermal facilities utilize sulfur and iron for metabolic activity; and in turn, what role that activity plays in initiating or promoting the development of a biofilm on plant substrates. Sulfur cycling is of interest because sulfur is produced in the resource. Iron is found in some of the steel formulations used in plant components and is also added as chemical treatment for reducing sulfide emissions from the plants. This report describes the set-up and operation of bioreactor for evaluating the response of colonies of geothermal organisms to changes in nutrient and environmental conditions. Data from initial experiments are presented and plans for future testing is discussed. 


\section{EXPERIMENTAL MATERIALS AND METHODS}

\subsection{Biological Media}

The biological inoculum was obtained from water samples collected from various geothermal plants during previous field studies. Geothermal fluid, collected from geothermal power plants, was filter sterilized by passing it through a 0.2 -micron pore size membrane filter. The filters were added to 10 milliliters $(\mathrm{ml})$ of sterile nutrient enriched TSB/trypticase soy broth and incubated for 24 hours at $35^{\circ} \mathrm{C}$ in a circulating water bath. A cell pellet was obtained by centrifugation, re-suspended in $10 \mathrm{ml}$ 's of fresh media and refrigerated until the test. Inoculum was also taken from selective culturing media used in a most probable number (MPN) analyses. Standard microbiological procedures were used throughout the preparation, handling and transfer of components.

\subsubsection{Experimental Apparatus}

Testing was performed in a Sixfors Model Fermentation Unit (INFORS Biotech Inc., Allentown, PA). The Sixfors, pictured below, is a multiple bioreactor system, allowing up to six separate fermentations to be performed in a relative small space. Each vessel has a working volume of $500 \mathrm{ml}$ with independent measurement and control of temperature, $\mathrm{pH}$, stirrer speed and dissolved oxygen. A feed pump can be set up to deliver medium to each vessel on a user-defined duty/delay cycle. Initial operating parameters can be downloaded from a liquid crystal display screen. A memory card system is used to store set-up data and set-point values to permit multiple users on the system. Up to three pumps per vessel allow for reagent and nutrient feeds and a number of other options and accessories are provided to allow the Sixfors to perform a wide range of tasks. The system is interfaced to a PC for data logging and control with IRIS NT4 software that has been designed to complement manual operation.

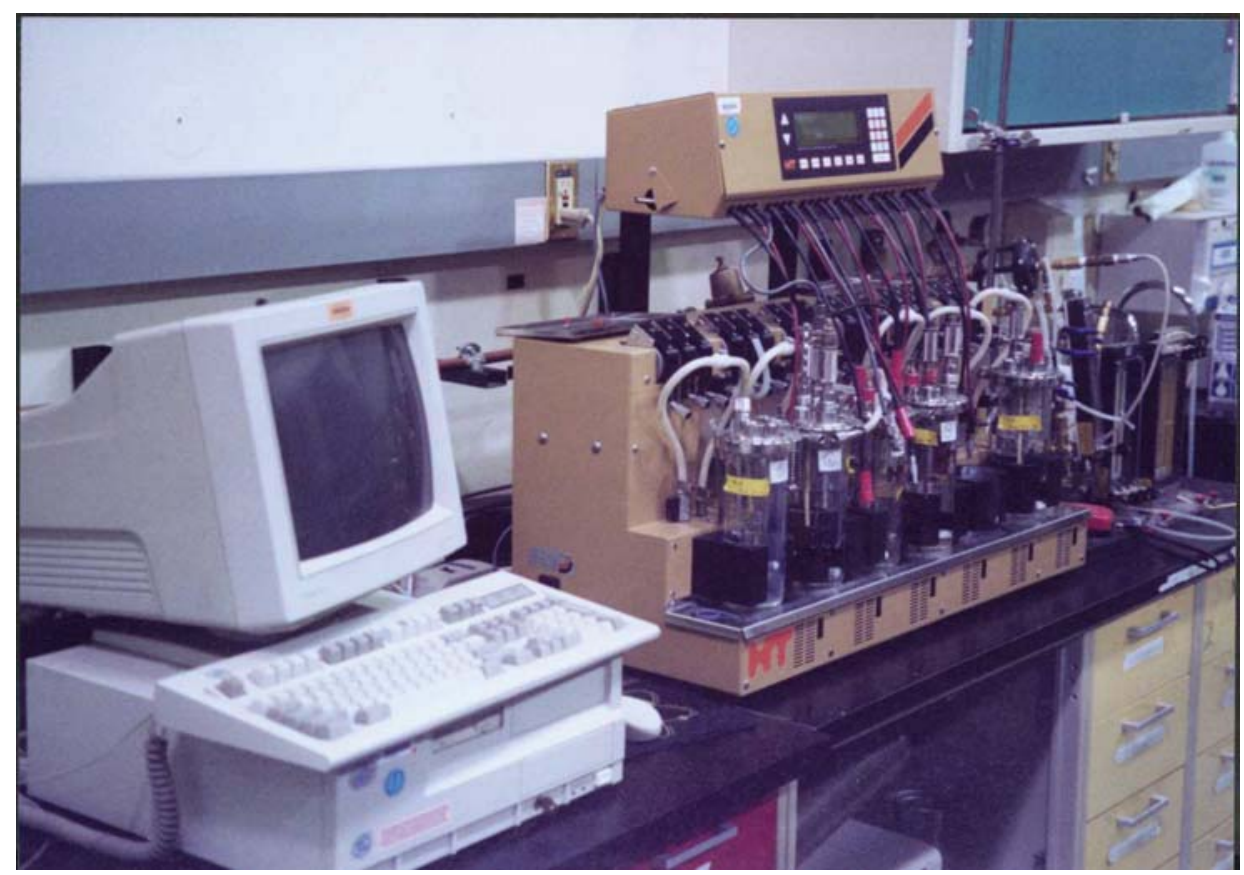

Figure 1. Sixfors Bioreactor 


\subsubsection{Sampling and Analyses}

During the experiments, samples were pulled from the air-sparging line of each bioreactor. The air line was removed and a $5 \mathrm{ml}$ syringe was attached to the port. The syringe was filled and emptied several times to ensure that liquid being sampled was from the bioreactor and did not contain material that was resident in the sparge line. The liquid was transferred to a sterile, $15 \mathrm{ml}$ conical centrifuge tube. A septum and aluminum seal cap was placed on the top of the tube and crimped into place making a tight seal. Immediately upon sealing the tube, approximately $0.7 \mathrm{ml}$ of the sample were withdrawn using a sterile $1 \mathrm{~mL}$ syringe. $0.1 \mathrm{ml}$ of this sample was added to a $1.5 \mathrm{ml}$, microcentrifuge tube containing $0.5 \mathrm{ml}$ of a $1 \% \mathrm{HCl}$ acid solution and $0.5 \mathrm{ml}$ of the sample was added to another microcentrifuge tube containing $0.5 \mathrm{ml}$ of a $4 \%$ glutaraldehyde solution. The $\mathrm{HCl}$ sample was used for ferrous iron analysis and the glutaraldehyde solution was used to preserve the sample for cell enumeration. The remaining portion of the sample in the tube was placed on ice and refrigerated for later analyses.

A $2.5 \mathrm{ml}$ sample was pulled from the conical centrifuge tube for carbon analysis. The sample was added to a $25 \mathrm{ml}$, volumetric flask containing approximately $10 \mathrm{ml}$ of nanopure water. The mixture was then brought to the mark with nanopure water for a $1 / 10$ dilution of the original sample. This mixture was then analyzed for total organic carbon (TOC). A $1 \mathrm{ml}$ sample was also pulled from the conical centrifuge tube for sulfate analysis.

A HACH Chemical DR/2010 Portable Datalogging Spectrophotometer was used to perform ferrous iron analyses. Program \#260 Ferrozine Method $\lambda 562$ (from Standard Methods for the Examination of Water and Wastewater) was modified in order to reduce the volume of sample required for analysis. A series of four standards plus a zero control were prepared and used for calibration. Samples and standards were transferred to ferrozine and then analyzed following a 5-minute interaction period.

The HACH Chemical DR/2010 Portable Datalogging Spectrophotometer was also used to conduct sulfate analyses. The analytical protocol is described in Program \#680, SulfaVer-4 Method. A portion of the sample was withdrawn form the sealed, $15-\mathrm{mL}$ conical centrifuge tube and placed into a $25 \mathrm{ml}$ graduated cylinder. The sulfaver powder pillow was added to the cylinder and the volume brought to the mark with nanopure water. The cylinder was sealed with parafilm and inverted several times. The solution was then transferred to a matched cell and the activity between the powder pillow and the sulfate was allowed to continue for the 5-minute incubation period. The concentration was determined by comparing the sample results to standards run under the same conditions.

Total organic carbon analyses were performed using a Model 700 TOC Analyzer (OIC Corporation). The analysis is based upon the conditions of Method 5310B- Combustion Infrared Method for Carbon Analyses (from Standard Methods for the Examination of Water and Wastewater). The samples are quantified using the values from three different standards and a zero-point determination.

Oxygen and $\mathrm{pH}$ are monitored using Ingold Electrode Sensors integrated with the Sixfors instrument for feedback and control of levels.

\section{RESULTS AND DISCUSSION}

\subsection{Test 1}

The experimental conditions for the first test is summarized in Table 1. For this test, two chambers of the Sixfors were used. One chamber, referred to as A, was filled with a filtered sample containing few 
organ-isms, while the second cell, B, contained the inoculated media. Samples were collected at 0.0, 1.0, $1.5,2.0,2.5,3.0$ and 5.0 hours.

Table 1. Test 1 Operating Conditions

\begin{tabular}{|l|l|}
\hline Test Duration & 340 minutes (5.67 hours) \\
\hline Number of Bioreactors & 2 A (filtered), B (inoculated) \\
\hline Stirrer Speed & $150 \mathrm{rpm}$ \\
\hline Temperature & $45^{\circ} \mathrm{C}$ \\
\hline $\mathrm{PH}$ & 7.0 \\
\hline Iron & $5 \mathrm{ml} 1000 \mathrm{ppm}$ Iron Chelate \\
\hline Cell Pellet & $5 \mathrm{ml}$ \\
\hline
\end{tabular}

The data plots depicting levels of dissolved oxygen $\left(\mathrm{O}_{2}\right)$ and total organic carbon (TOC) are presented in Figures 3 and 4, respectively. The initial peak in the $\mathrm{O}_{2}$, measured in the filtered sample, is due to an air bubble, which formed on the electrode tip. The $\mathrm{O}_{2}$ plots show slight declines and the TOC levels are slightly elevated which may be due to biological growth, but neither is significant. No changes in iron or sulfate levels were detected. Test results may have been comprised by operation at high temperature. (Originally, a set-point of $25^{\circ} \mathrm{C}$ was entered into system but may not have been saved properly by the program that operates the Sixfors.) The higher temperature may have killed some of the organisms in the inoculated vessel.

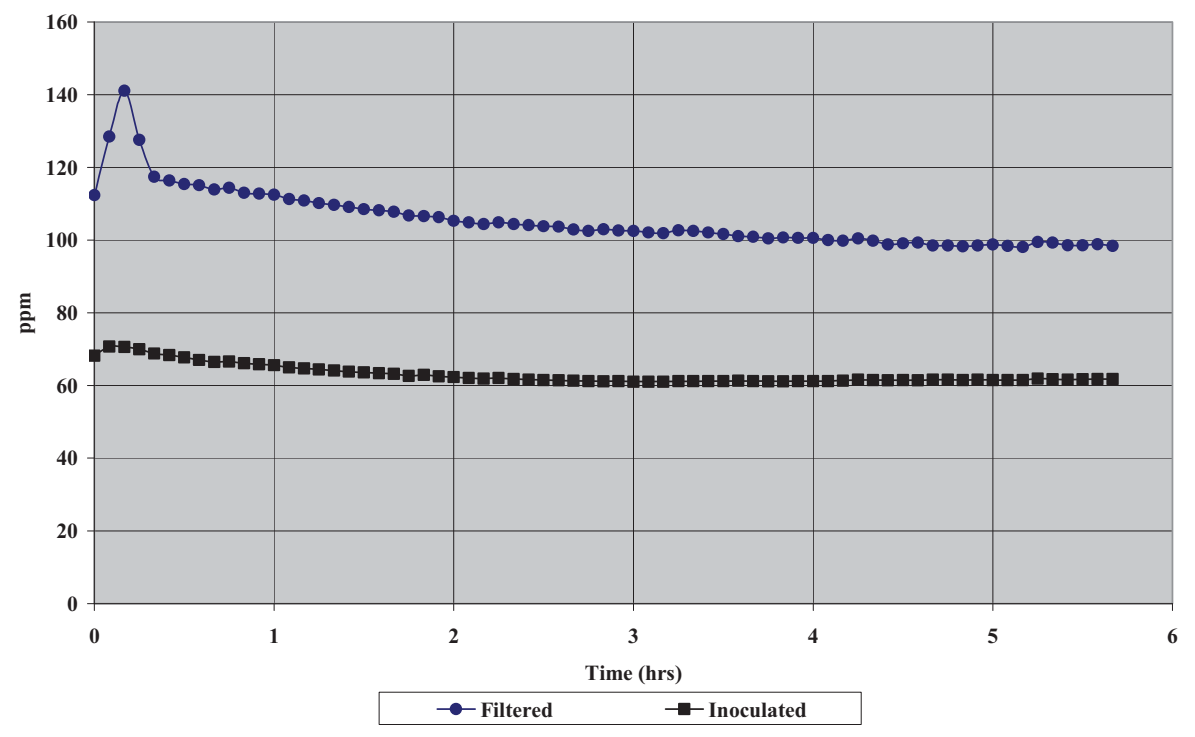

Figure 2. Test 1 Dissolved Oxygen Data 


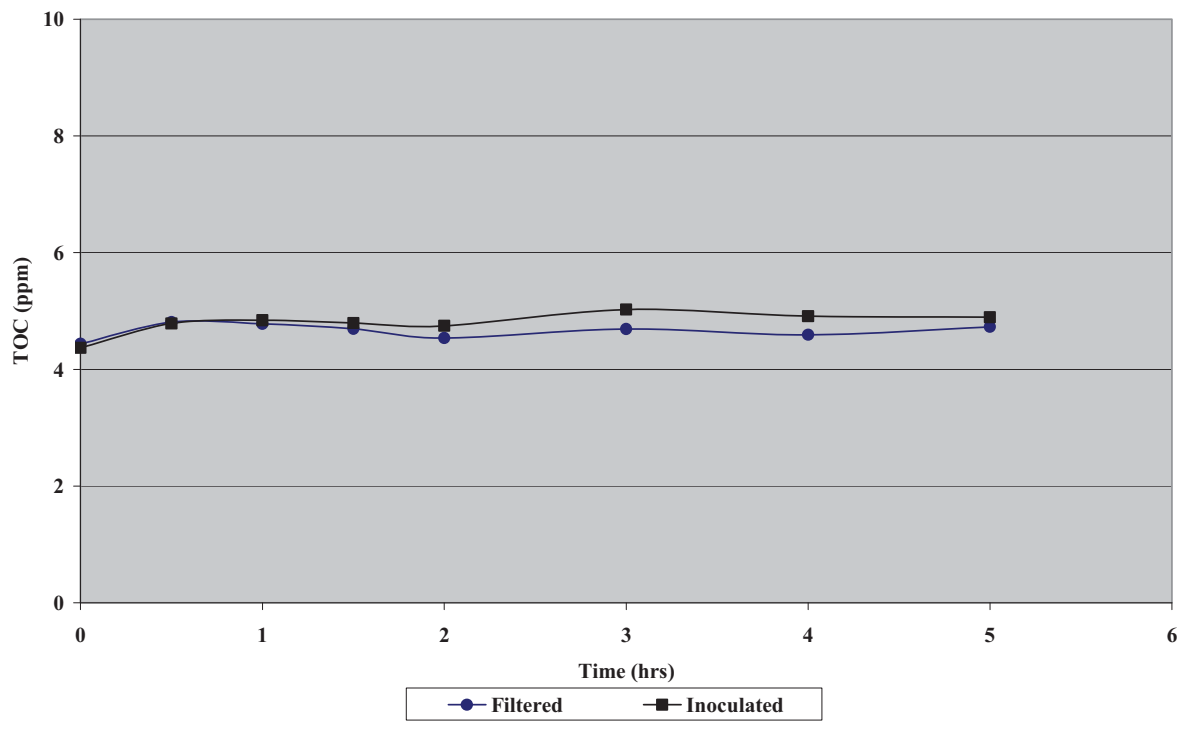

Figure 3. Test 1 TOC Data

\subsection{Test 2}

The experimental conditions used in Test 2 are summarized in Table 2. In Test 2 care was taken to make sure that the system recognized the $25^{\circ} \mathrm{C}$ set-point. The amount of iron chelate added at the beginning of the experiment was increased to provide a higher overall concentration of iron in the solution to facilitate analyses. Two bioreactors, one inoculated and one control, were used with no aeration. Sampling was performed at 0.0, 1.0, 1.5, 2.0, 2.5, 3.0, 5.0, 11.0,18.0 and 24.0 hours.

Table 2. Test 2 Operating Conditions

\begin{tabular}{|l|l|}
\hline Test Duration & 1522 minutes (25.37 hours) \\
\hline Number of Bioreactors & 2 A (filtered), B (inoculated) \\
\hline Stirrer Speed & $200 \mathrm{rpm}$ \\
\hline Temperature & $25^{\circ} \mathrm{C}$ \\
\hline $\mathrm{PH}$ & 7.0 \\
\hline Iron & $10 \mathrm{ml} 1000 \mathrm{ppm}$ Iron Chelate \\
\hline Cell Pellet & $5 \mathrm{ml}$ \\
\hline
\end{tabular}

The dissolved oxygen and TOC data from Test 2 are presented in Figures 4 and 5. The iron chelate was added to the inoculated bioreactor at the start of the test and then added to the control (filtered) reactor after realizing that the systems needed to be balanced. Upon adding the chelate, the TOC values 
for both systems were similar. The dissolved oxygen, measured in the inoculated chamber is seen to decrease in concentration over the test period as compared to the filtered, or control, vessel containing few micro-organisms. (The initial offset between the plots is due calibration offset and should be discounted, i.e. only changes in value of individual plots are meaningful.) The decrease in oxygen is indicative of increased activity in the inoculated chamber. The TOC analyses also show a small increase in the inoculated reactor. Again, there was no measurable change in the iron or sulfate levels.

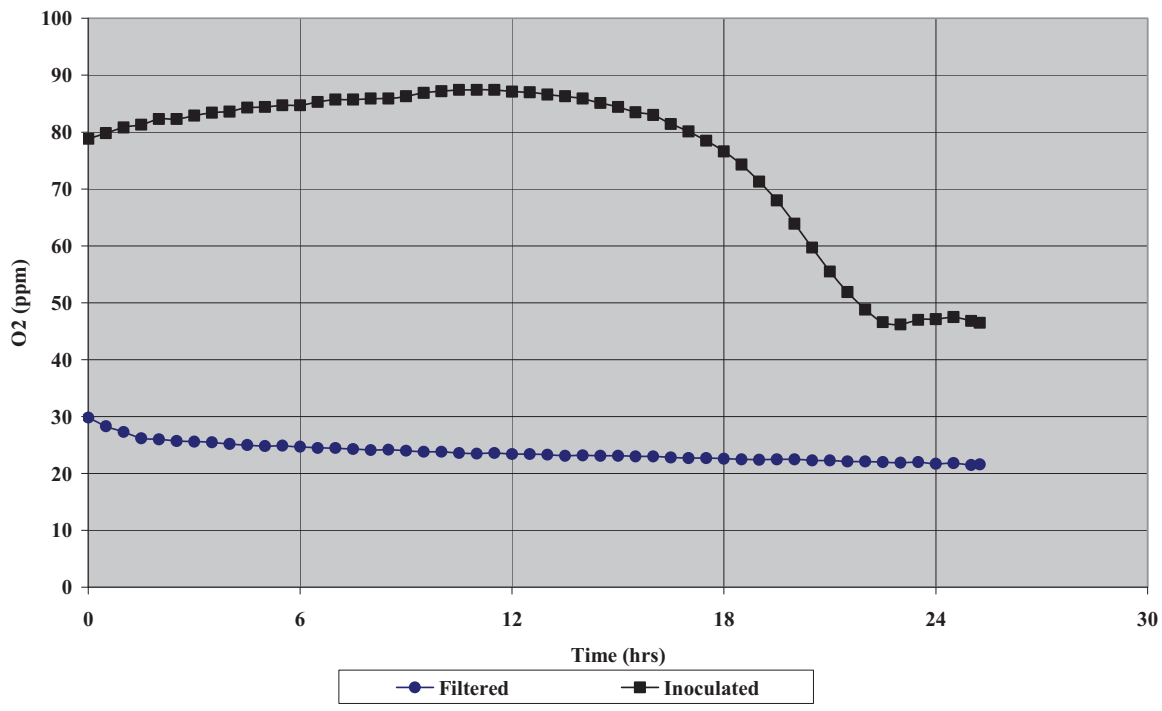

Figure 4. Test 2 Dissolved Oxygen Data

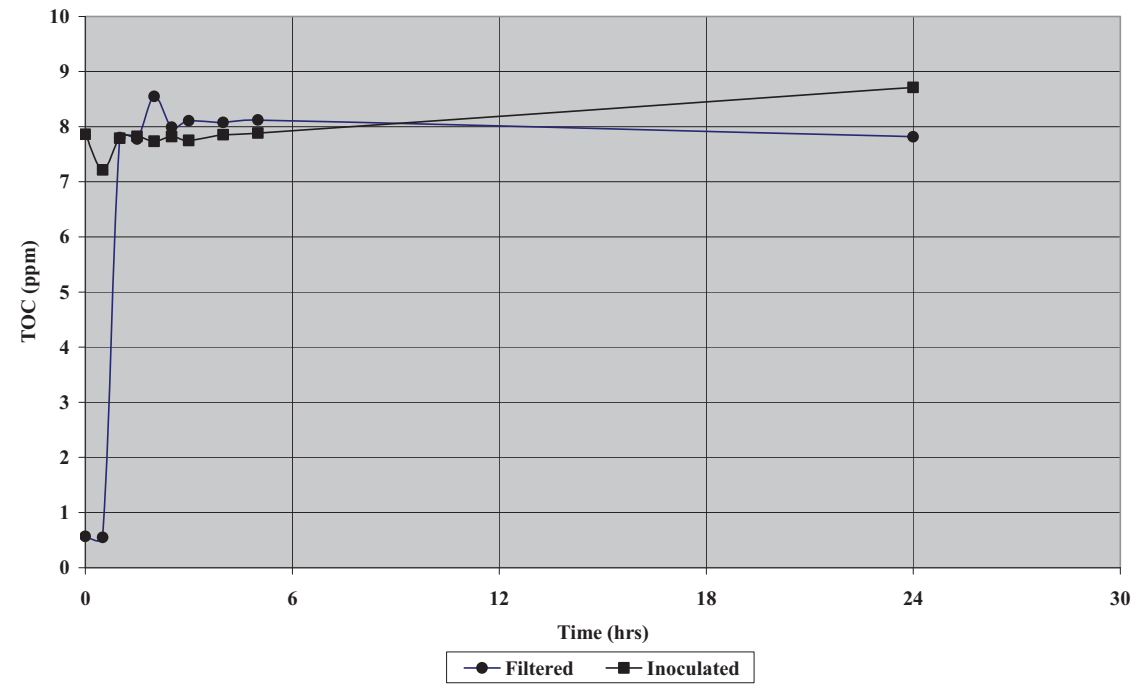

Figure 5. Test 2 TOC Data 


\section{$3.3 \quad$ Test 3}

The experimental conditions for Test 3 are presented in Table 3.

Table 3. Test 3 Operating Conditions

\begin{tabular}{|l|l|}
\hline Test Duration & 4707 minutes (78.45 hours) \\
\hline Number of Bioreactors & 2 A (filtered), B (inoculated) \\
\hline Stirrer Speed & $200 \mathrm{rpm}$ \\
\hline Temperature & $30^{\circ} \mathrm{C}$ \\
\hline PH & 7.0 \\
\hline Iron & $10 \mathrm{ml} 1000 \mathrm{ppm}$ Iron Chelate \\
\hline Cell Pellet & $5 \mathrm{ml}$ \\
\hline
\end{tabular}

The testing protocol was similar to the previous experiments, but extended over a longer period of time in order to allow more biomass to build in the system and see if that would allow the detection of changes in iron or sulfate. The temperature set-point was adjusted to a slightly higher level $\left(30^{\circ} \mathrm{C}\right)$ due to the difficulties with controlling the system at $25^{\circ} \mathrm{C}$. (Room temperatures exceeded $25^{\circ} \mathrm{C}$ during Test 2 , causing the control problem.) Samples were collected at 0.0, 1.5, 2.0, 2.5, 3.0, 5.0, 11.0, 18.0, 24.0, 36.0, $48.0,60.0$, and 72.0 hours.

The dissolved oxygen, TOC and iron analyses are shown in Figures 6-8. During this test a solution of trypticase soy broth (TSB) was added prior to the sample collection at the 48 -hour time interval. (This material is a source of carbon and nutrients.) There was a noticeable increase in the TOC measurements at this time. There was a similar spike in the ferrous iron in the inoculated bioreactor. This is may be an indication of microbial activity. We did not see the same spike in the filtered bioreactor. The plot of oxygen also showed a stronger and deeper level of decrease in the inoculated bioreactor. This is another indication of microbial activity. The organisms may be metabolizing the carbon removing oxygen from the solution during the process. The recovery periods were about the same for each reactor, with little change after the 60-hour time frame. There was no appreciable increase in sulfate levels detected. 


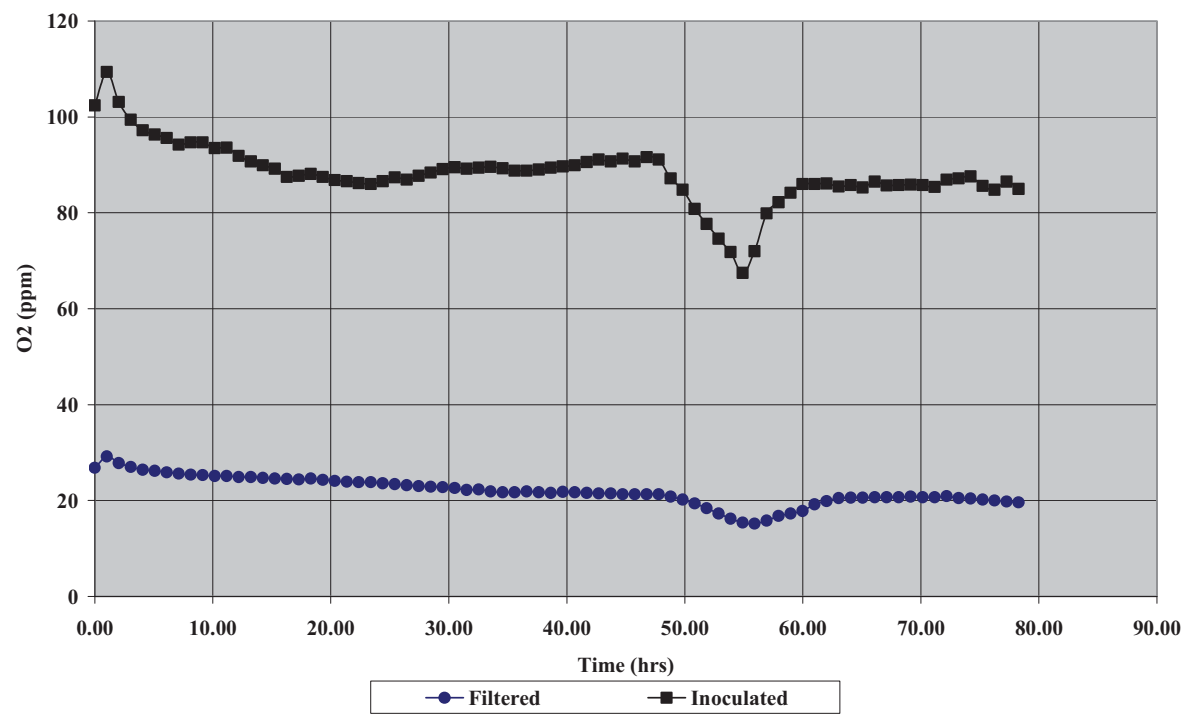

Figure 6. Test 3 Dissolved $\mathrm{O}_{2}$ Data

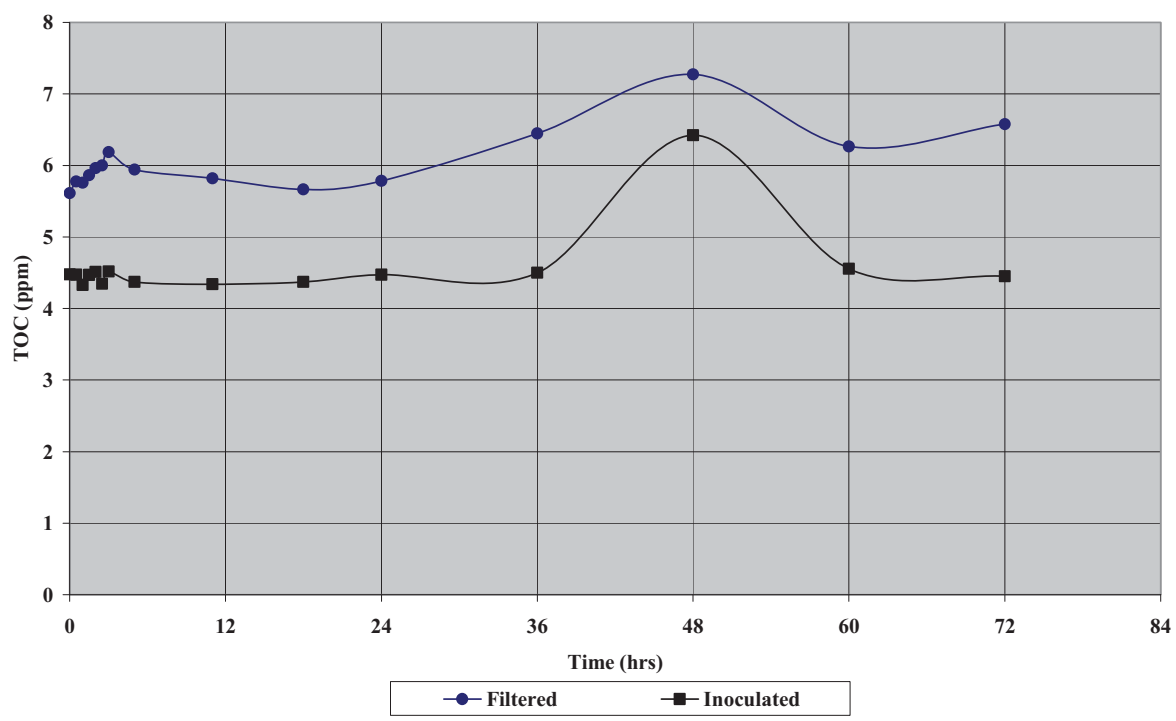

Figure 7. Test 3 TOC Data 


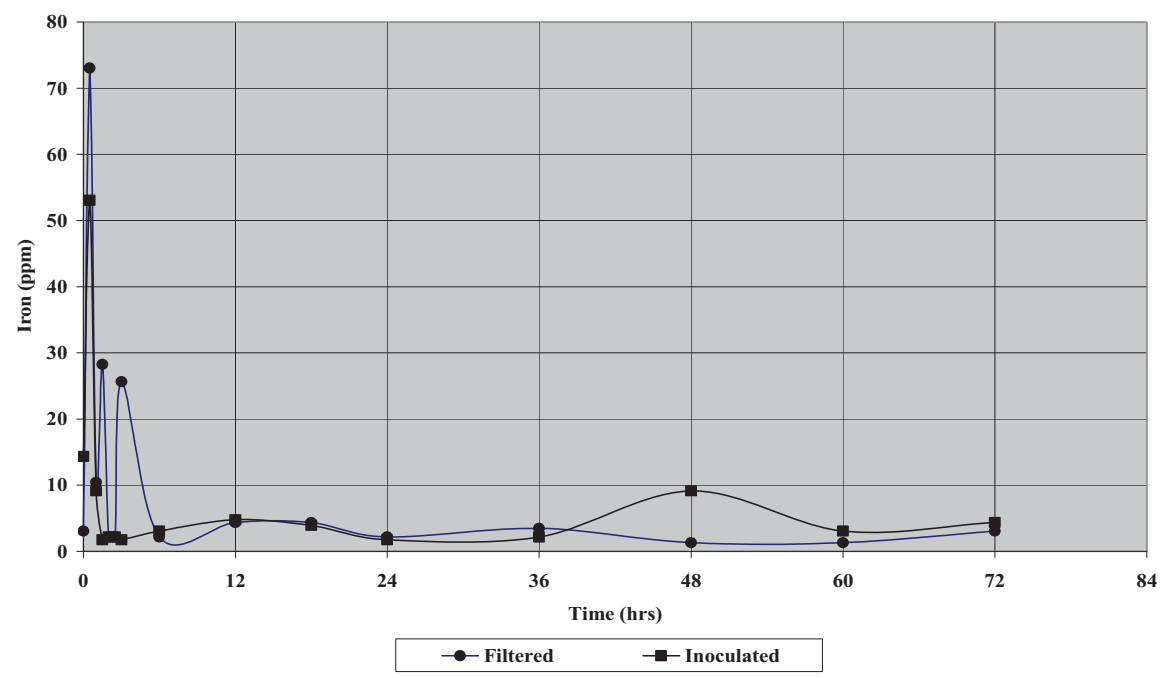

Figure 8. Test 3 Iron Analyses

\section{$3.4 \quad$ Test 4}

For Test 4, described in Table 4, two additional bioreactors were added in order to conduct the experiments under both anaerobic and aerobic conditions. All cells were initially purged with air, then the air supply was terminated to two of the reactors and replaced with a nitrogen purge. The remainder of the cell pellet prepared for Test 3 was added to the culture media in an attempt to increase the biomass produced. The sulfate concentration was increased 24 hours into the test, when a sterile stock solution was added to each reactor, bringing the sulfate concentration up to $1000 \mathrm{ppm}$ above the normal operating range of $300 \mathrm{ppm}$. (An error was made in that only $5 \mathrm{ml}$ 's of iron chelate was introduced into the reactors.) Sampling was performed at 0.0, 1.0, 1.5, 2.0, 2.5, 3.0, 5.0, 9.0, 12.0, 18.0, 24.0, 30.0, 36.0, 48.0, 60.0, and 72.0 hours.

Table 4. Test 4 Operating Conditions

\begin{tabular}{|l|l|}
\hline Test Duration & 4356 (72.60 hours) \\
\hline Number of Bioreactors & $\begin{array}{c}\text { C, A(Filtered) B (inoculated) } \\
\text { C(Filtered) D (inoculated) }\end{array}$ \\
\hline Stirrer Speed & $200 \mathrm{rpm}$ \\
\hline Temperature & $30^{\circ} \mathrm{C}$ \\
\hline PH & 7.0 \\
\hline Iron & $10 \mathrm{ml} 1000 \mathrm{ppm}$ Iron Chelate \\
\hline Cell Pellet & $2 \mathrm{ml}$ \\
\hline Nitrogen Sparging & $\mathrm{C} \mathrm{\&} \mathrm{D}$ \\
\hline 50,000 ppm Sulfate & $5 \mathrm{ml}$ (added after 24 hours) \\
\hline
\end{tabular}


During the testing, the nitrogen-sparged, inoculated bioreactor lost temperature control and experienced an excursion up to $57^{\circ} \mathrm{C}$. It took approximately one hour for it to regain control and then an additional two or three hours before the reactor cooled to its design test parameter. This excursion may have affected the organisms impacting the data comparisons.

The dissolved oxygen, TOC and iron analyses for Test 4 are shown in Figures 9-11. There were noticeable changes in the oxygen profile and iron concentrations upon the addition of the concentrate, consistent with increased microbiological activity. No appreciable change in sulfate was detected.

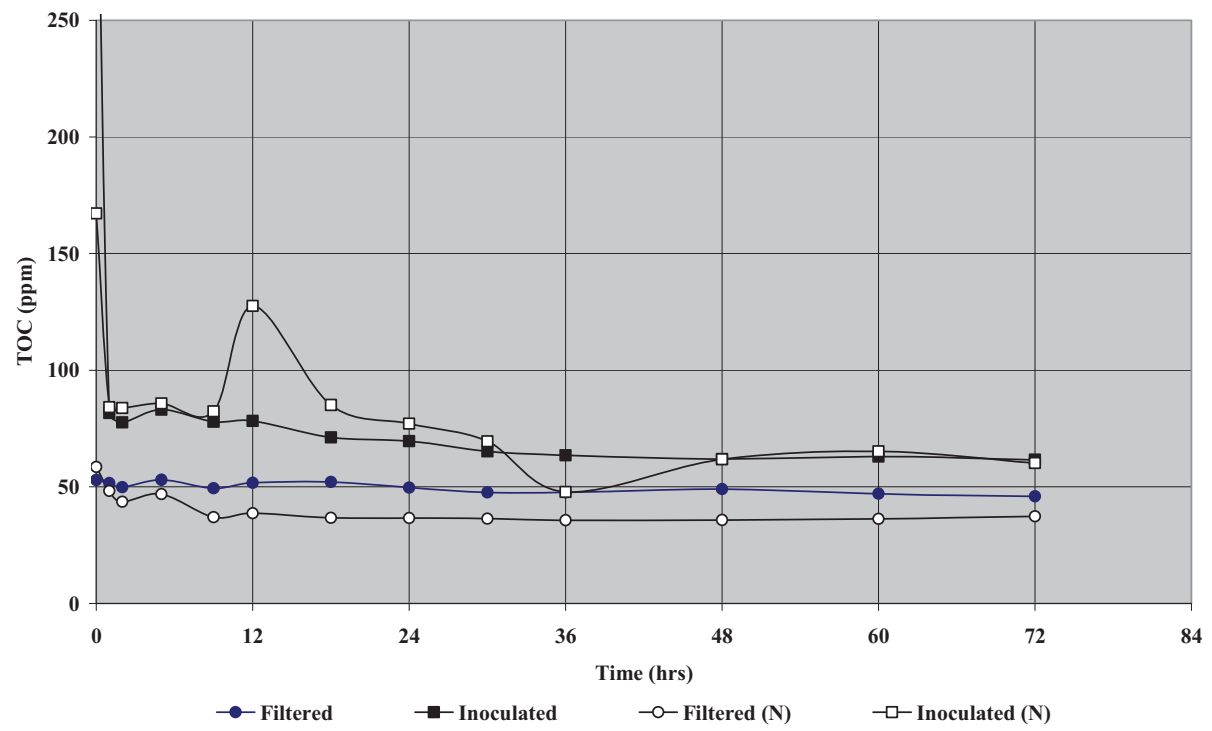

Figure 9. Test 4 Dissolved Oxygen Data 


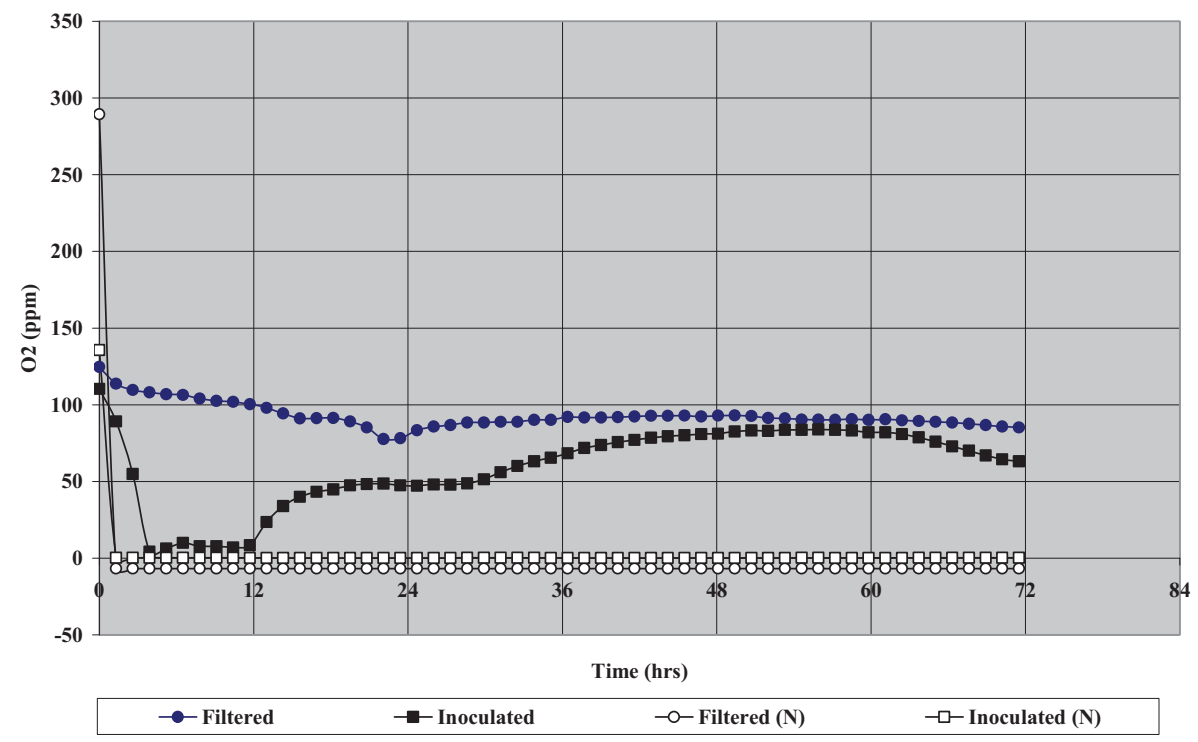

Figure 10. Test 4 TOC Data

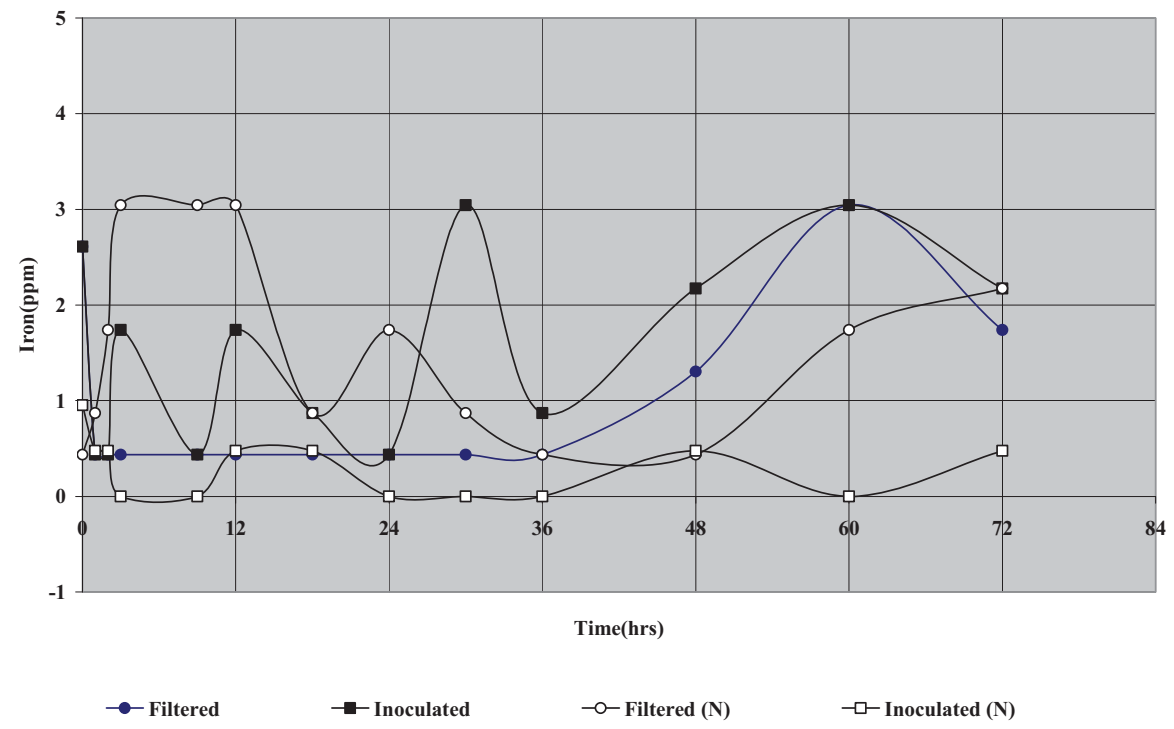

Figure 11. Test 4 Iron Analyses

\section{$3.5 \quad$ Test 5}

Test 5 was operated under similar conditions (see Table5) as Test 4, with the intent of collecting data without the interference of the temperature excursion. In addition, a different media was used as the inoculum. For this test, material from MPN studies to determine numbers of iron reducing bacteria, conducted during a recent sampling trip to Bonnet Geothermal (Cove Fort, UT), were added to the filtered water samples. The tests were conducted over a 72 hour period with samples collected at $0.0,0.5,1.0$, 2.0, 3.0, 6.0, 12.0, 24.0, 30.0, 36.0, 48.0, 60.0, 72.0, 73.0, and 90.0 hours. Again, a concentrated sulfate 
solution was added just prior to the 24-hour sampling period and a mixture of organic acids were also added to stimulate biological growth around hour 60 of the test.

Table 5. Test 5 Operating Conditions

\begin{tabular}{|l|l|}
\hline Test Duration & 5911 (98.52 hours) \\
\hline Number of Bioreactors & $\begin{array}{c}4, \mathrm{~A}(\text { Filtered) B (inoculated) } \\
\text { C(Filtered) D (inoculated) }\end{array}$ \\
\hline Stirrer Speed & $200 \mathrm{rpm}$ \\
\hline Temperature & $35^{\circ} \mathrm{C}$ \\
\hline $\mathrm{pH}$ & 7.0 \\
\hline Iron & $10 \mathrm{ml} 1000$ ppm Iron Chelate \\
\hline Cell Pellet & $5 \mathrm{ml}$ \\
\hline Nitrogen Sparging & $\begin{array}{l}\mathrm{C} \& \mathrm{D} \text { (changed to A \& B at 73 } \\
\text { hours) }\end{array}$ \\
\hline 50,000 ppm Sulfate & $5 \mathrm{ml}$ (added after 24 hours) \\
\hline Organic Acids & $5 \mathrm{ml}$ (added after 60 hours) \\
\hline
\end{tabular}

Plots of the dissolved oxygen, TOC, and iron analyses collected during Test 5 are presented in Figure 12- 14. The increase in carbon associated with the addition of the organic acids is evident on the TOC plots. Similarly, there was a significant decrease in the oxygen content of the two aerobic cells, indicative of metabolic activity. Both dropped to zero shortly following the addition of the organic acids. At the 72-hour point in the experiment, all of the bioreactors were purged with air for one hour. At the end of air purging nitrogen purging was initiated in the two cells that were originally aerobic and all purging was stopped in the two cells that initially received nitrogen. Both of these bioreactors exhibited decreases in the oxygen profile. At the 72-hour point in the experiment, all of the bioreactors were purged with air for one hour. After the air purge, nitrogen purging was initiated in the two cells that were originally aerobic and all purging was stopped in the two cells that initially received nitrogen. Both inoculated bioreactors showed an increase in reduced iron. Again, no change in sulfate levels was observed.

The fact that the filtered cell also showed a rapid and continuous decrease in oxygen may be associated with growth due to incomplete filtration or contamination. The control sample was filter sterilized by passing it through a 0.2 -micron pore size filter. (Steam sterilization was not performed since it could impact the chemical nature of the solution.) The filtering does not guarantee that all organisms will be eliminated from the control, and over time there could be some growth. And, while every attempt was made to avoid contaminating the control sample, it is possible that with multiple sampling over a period of time, it may occur. 


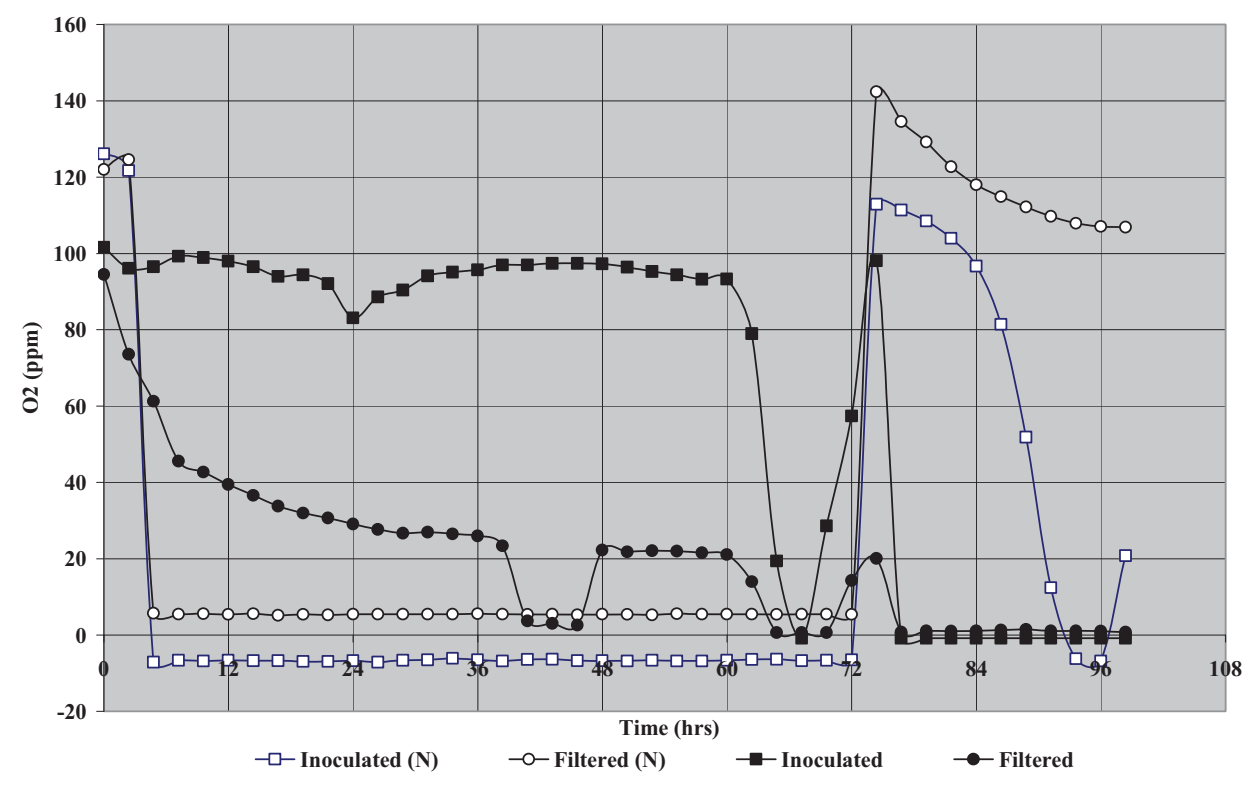

Figure 12. Test 5 Dissolved Oxygen Data

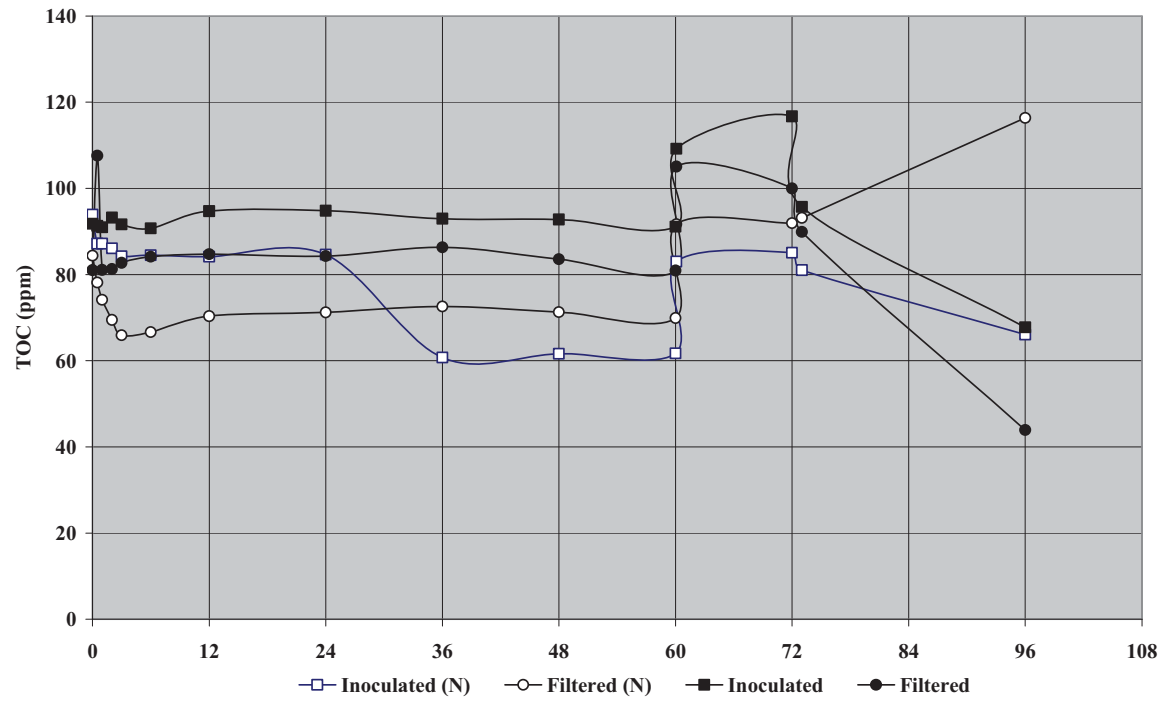

Figure 13. Test 5 TOC Data 


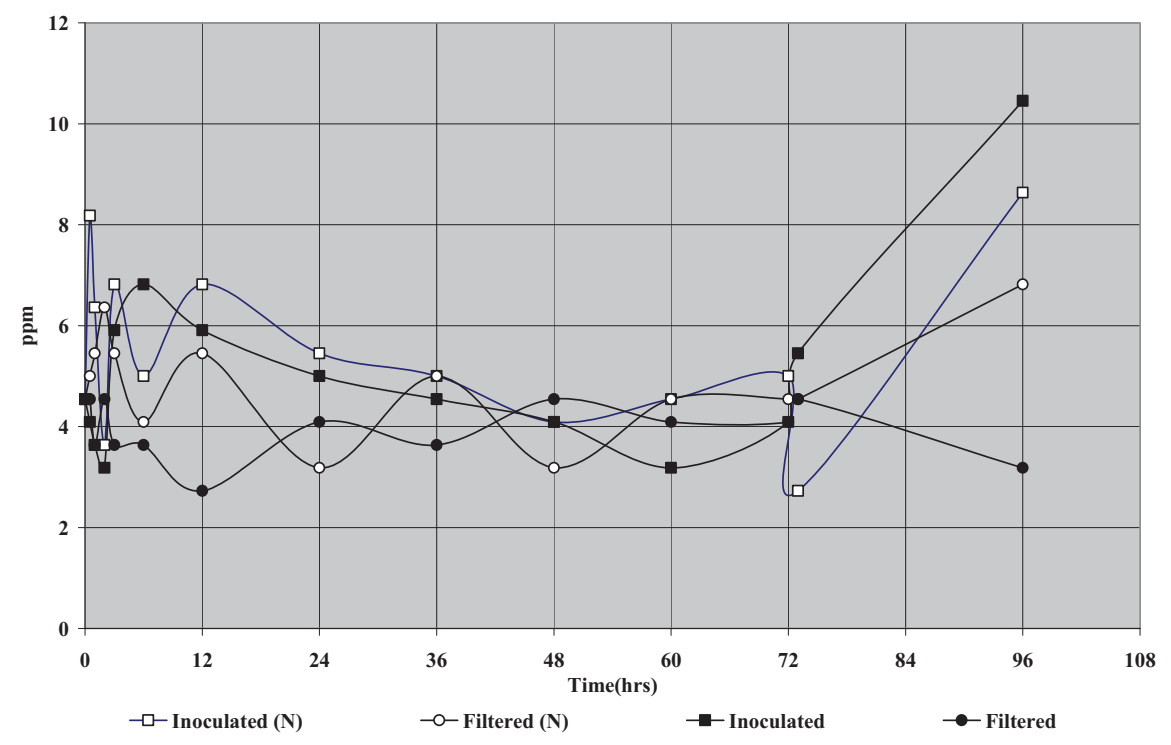

Figure 14. Test 5 Iron Analyses

\subsection{Test 6}

Test 6 investigated the effects of operating a lower $\mathrm{pH}$ (4.0). As in Test 5, the inoculum was derived from MPN media, including acid-forming, iron-reducing, sulfate-reducing and denitrifying types, collected at the Bonnet facility in Utah. Serum vials of media were incubated for 24 hours in a water bath at $35^{\circ} \mathrm{C}$. A cell pellet was then prepared by centrifugation. Initially, all the bioreactors were purged with air. The air purge was then discontinued in two of the reactors, while a nitrogen purge was established in the other two reactors. At 72 hours the four bioreactors were again sparged with air for sixty minutes and then the air was turned off to the two previously anaerobic, or nitrogen purged cells, and the aerobic cells were sparged with nitrogen to force them anaerobic. A mixture of organic acids was added to each bioreactor at 24 hours and the sulfate concentration was increased at 48 hours. Samples were collected at $0.0,0.5,1.0,2.0,3.0,6.0,12.0,24.0,30.0,36.0,48.0,60.0,72.0,73.0$, and 90.0 hours 
Table 6. Test 6 Operating Conditions

\begin{tabular}{|l|l|}
\hline Test Duration & 5425 (90.42 hours) \\
\hline Number of Bioreactors & $\begin{array}{c}4, \text { A(Filtered) B (inoculated) } \\
\text { C(Filtered) D (inoculated) }\end{array}$ \\
\hline Stirrer Speed & $200 \mathrm{rpm}$ \\
\hline Temperature & $35^{\circ} \mathrm{C}$ \\
\hline PH & 4.0 \\
\hline Iron & $10 \mathrm{ml} 1000 \mathrm{ppm}$ Iron Chelate \\
\hline Cell Pellet & $2.5 \mathrm{ml}$ \\
\hline Nitrogen Sparging & $\begin{array}{l}\mathrm{C} \& \text { D (changed to A \& B at } 73 \\
\text { hours) }\end{array}$ \\
\hline 50,000 ppm Sulfate & $5 \mathrm{ml}$ (added after 48 hours) \\
\hline Organic Acids & $5 \mathrm{ml}$ (added after 24 hours) \\
\hline
\end{tabular}

Plots of the dissolved oxygen, TOC and iron analyses are found in Figures 15-17. There was a gradual increase in the concentration of ferrous iron for the first 36 hours, decreasing by the 48 hour sampling period. No changes in sulfate levels were detected.

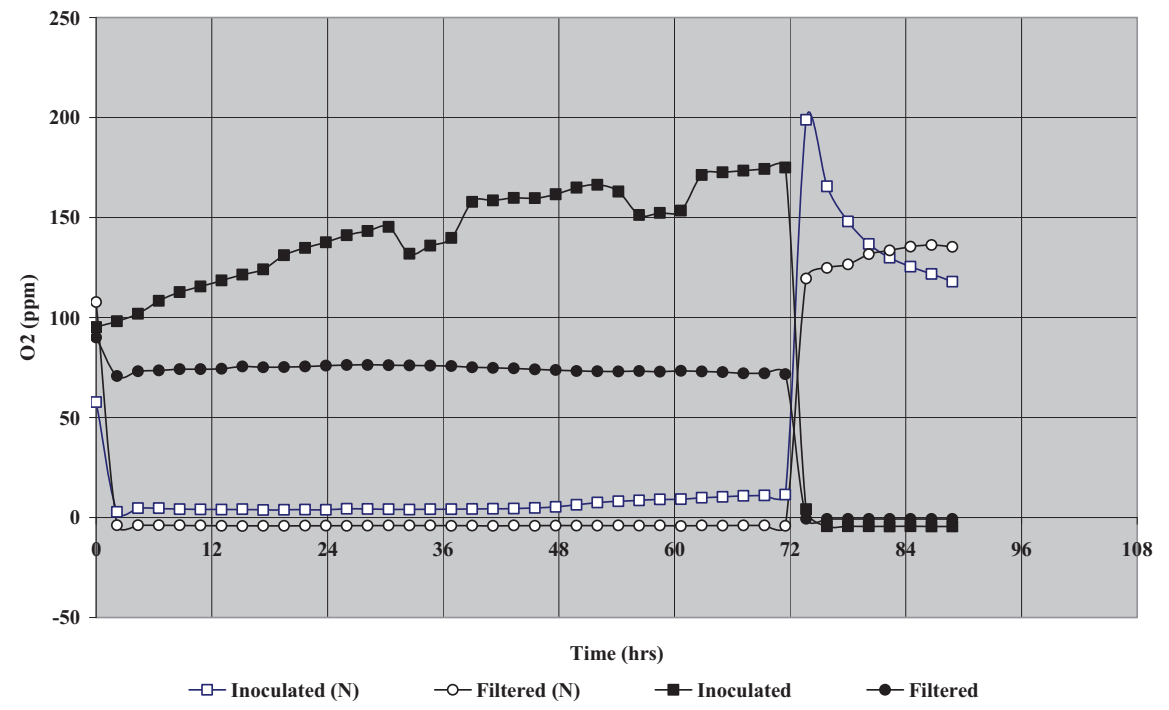

Figure 15. Test 6 Dissolved Oxygen Data 


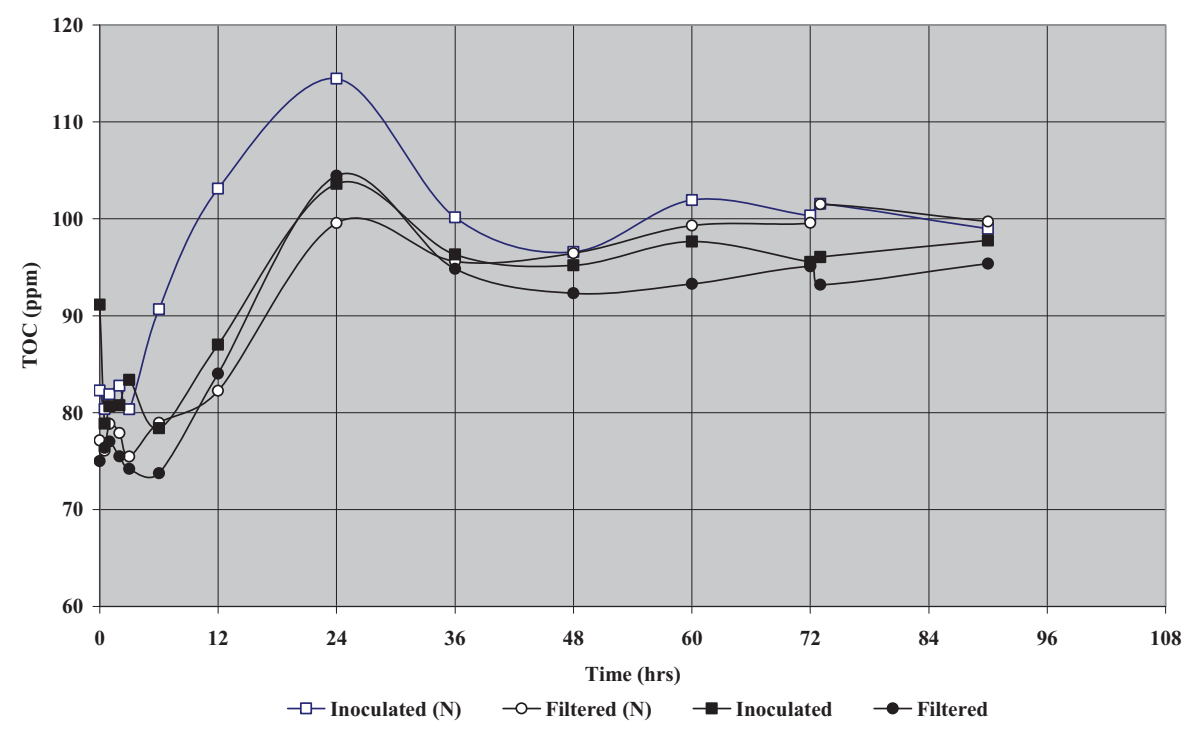

Figure 16. Test 6 TOC Data

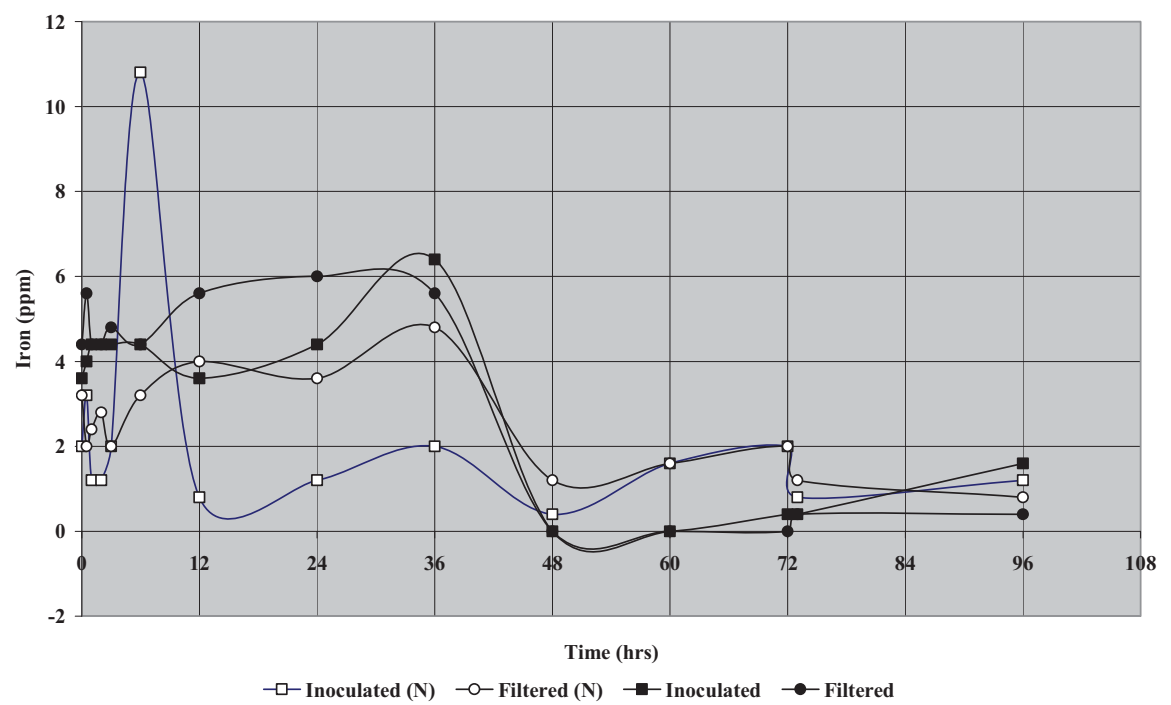

Figure 17. Test 6 Iron Analyses

\section{$3.7 \quad$ Test 7}

Test 7 was run under alkaline conditions at a $\mathrm{pH}$ of 9.0 under similar conditions as Test 6 . The inoculum consisted of materials from recent bioreactor studies. Cell pellets left over from the previous tests were transferred to serum bottles containing iron-reducing media. One milliliter of $12500 \mathrm{ppm}$ sulfate solution was added to four $25 \mathrm{ml}$ serum bottles. Also $2.5 \mathrm{ml}$ 's of an organic acid mixture was 
injected into each sterile vial. All serum bottles were placed in a circulation water bath set at $35^{\circ} \mathrm{C}$, and incubated for 24 hours. A final cell pellet was obtained by centrifugation just before the initiation of the test. All of the bioreactors were purged initially with air, then the air supply was stopped in two of the bioreactors $(\mathrm{A} \& \mathrm{~B})$ while the other two bioreactors $(\mathrm{C} \& \mathrm{D})$ were purged with nitrogen. At 72 hours all bioreactors were purged with air for sixty minutes then the air was turned off to cells $\mathrm{C} \& \mathrm{D}$ while bioreactors A \& B were purged with nitrogen to force them into anaerobic status. A mixture of organic acids was added to each bioreactor at time 24 hours. The sulfate concentration was increased at $48 \mathrm{hrs}$ in the test. The temperature was maintained at $35^{\circ} \mathrm{C}$. Samples were collected at times: 0.0, 0.5,1, 2, 3, 6, $12,24,30,36,48,60,72,73$, and 90 hours.

Table 7. Test 7 Operating Conditions

\begin{tabular}{|l|l|}
\hline Test Duration & 5424 (90.40 hours) \\
\hline Number of Bioreactors & $\begin{array}{c}4, \mathrm{~A}(\text { Filtered) B (inoculated) } \\
\text { C(Filtered) D (inoculated) }\end{array}$ \\
\hline Stirrer Speed & $200 \mathrm{rpm}$ \\
\hline Temperature & $35^{\circ} \mathrm{C}$ \\
\hline PH & 9.0 \\
\hline Iron & $10 \mathrm{ml} 1000$ ppm Iron Chelate \\
\hline Cell Pellet & $2.5 \mathrm{ml}$ \\
\hline Nitrogen Sparging & $\begin{array}{l}\mathrm{C} \& \mathrm{D} \text { (changed to A \& B at } 73 \\
\text { hours) }\end{array}$ \\
\hline 50,000 ppm Sulfate & $5 \mathrm{ml}$ (added after 48 hours) \\
\hline Organic Acids & $5 \mathrm{ml}$ (added after 24 hours) \\
\hline
\end{tabular}

The data from this experiment is presented in Figures 18-20. The oxidation/reduction potential at this $\mathrm{pH}$ is less conducive to the support of soluble reduced metals. This trend is illustrated by the quick disappearance of the iron in the test reactors and the lack of ferrous iron detected in subsequent samples. All measurements at this $\mathrm{pH}$ indicated less biological activity than previous tests. Miscellaneous noise spikes were recorded by the oxygen probe, which was placed in the filtered test reactor. These spikes may be due to the mechanical condition of the probe. 


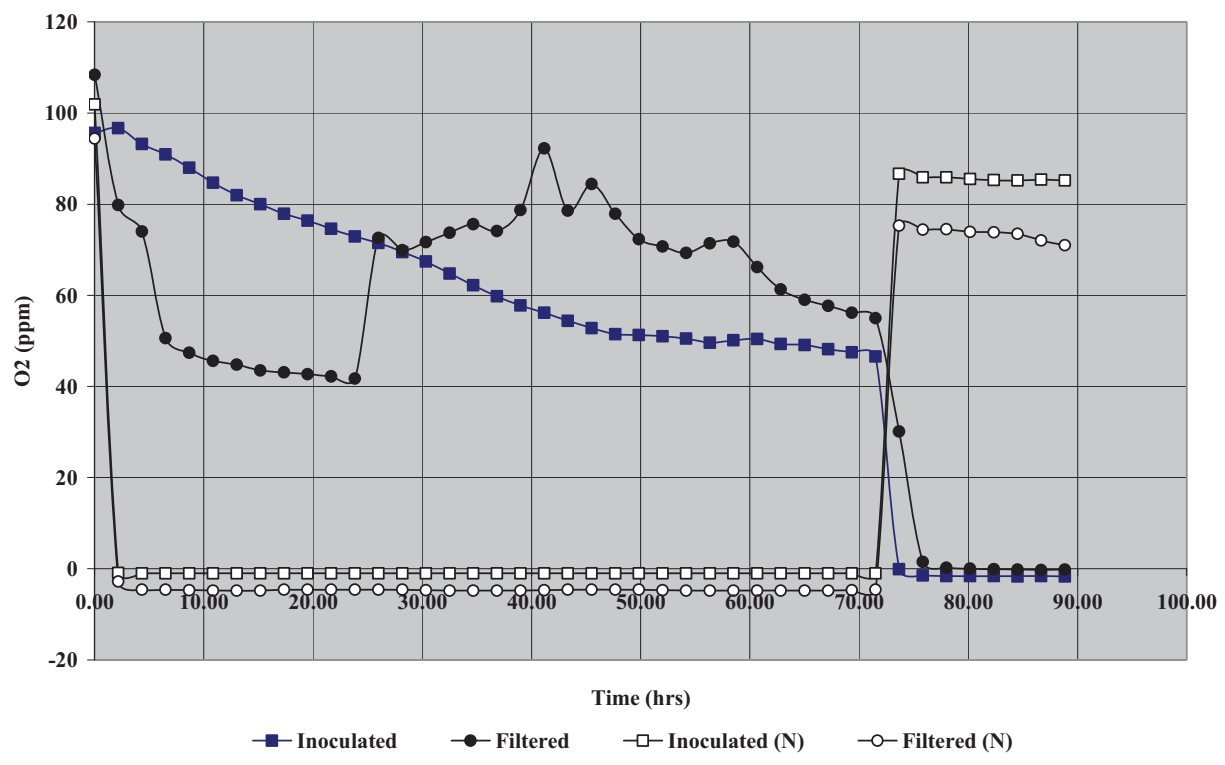

Figure 18. Test 7 Dissolved Oxygen Data

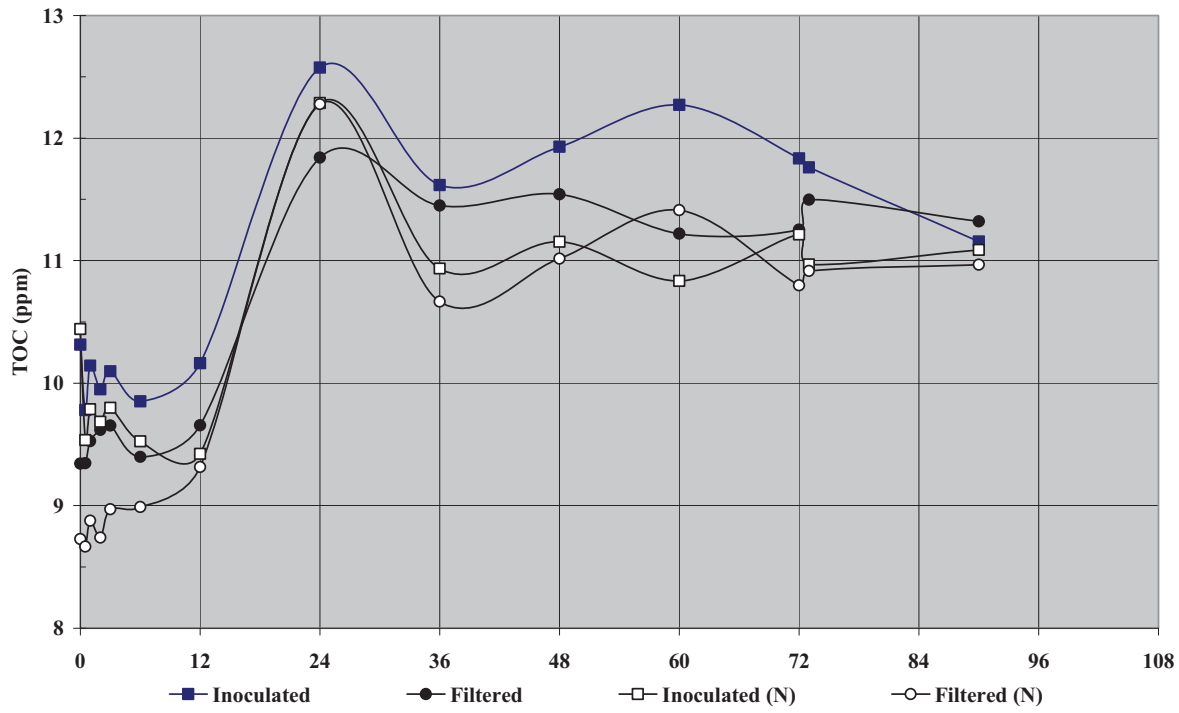

Figure 19. Test 7 TOC Data 


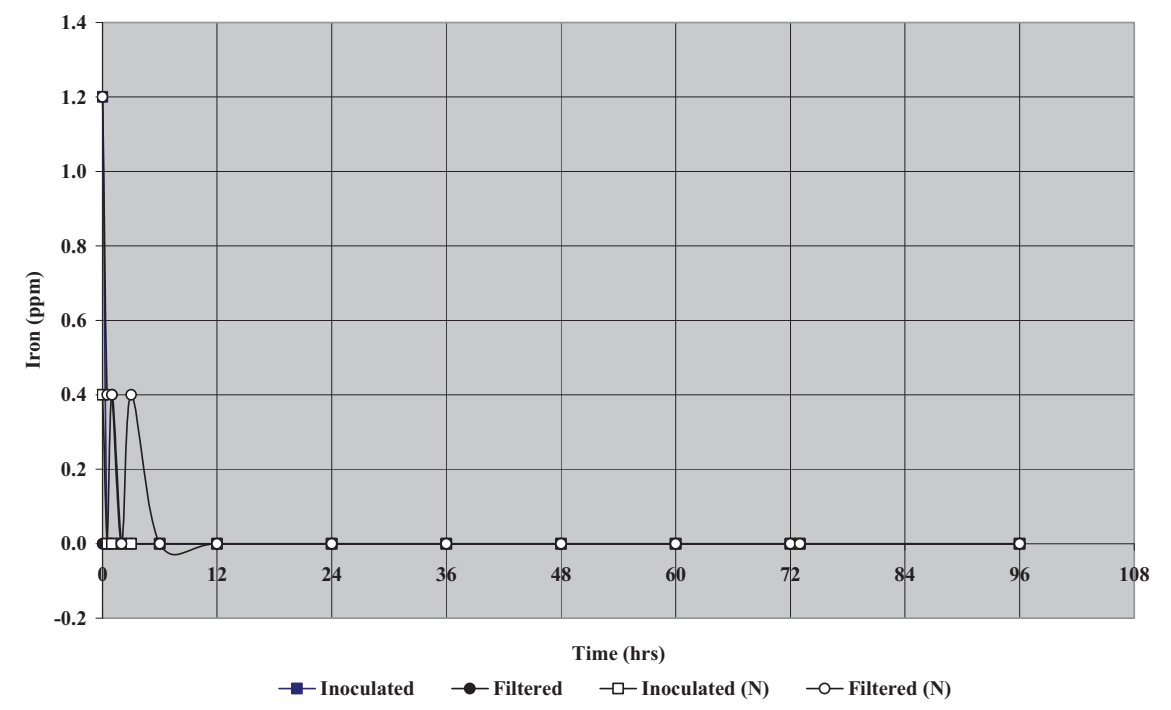

Figure 20. Test 7 Iron Analyses

\section{CONCLUSIONS AND RECOMMENDATIONS FOR FUTURE WORK}

A series of scoping experiments have been performed to investigate how microorganisms found at geothermal plants respond to changes in the physiochemical properties of their environment. While not all the parametric changes were intentional (i.e. the unplanned temperature excursions), they all illustrate how these perturbations can alter the metabolic activities of the organisms.

The testing did show some evidence that the iron chelate material used in the abatement of hydrogen sulfide in many facilities is degraded by the microorganisms found there. Additional testing is planned with tighter controls to minimize contamination of the filtered sample in order that degradation rates can be more accurately determined.

No changes in sulfate were measured during the tests. This result was surprising; however, there are several explanations as to why changes may not have been observed. First, the consortia of organisms used in the testing may have preferred the iron substrate. That is there may have been a larger population of iron reducers in our media. Also, the testing may not have been conducted at a low enough redox potential for sulfate reduction to occur. There may have been enough oxygen leakage into our chambers so that a strict anaerobic environment was not maintained. Additional testing using organisms cultured for sulfate reduction and tighter controls over the operational parameters is planned to address these questions. 